\title{
The influence of spiritual leadership on turnover intention: assessing mediating role of quality of work life and moderating role of organization climate
}

\author{
Neema Gasper Mariwa*, Garba Betchem, Isaac Amankwaa Adu, \& Minkah Yaw Andrews \\ School of Management Jiangsu University, 301 Xuefu Road, Zhenjiang 212013, China
}

\begin{abstract}
The purpose of this study is to investigate the influence of spiritual leadership on employees' turnover intention by assessing the role of quality of work life as a mediating role and organizational climate as a moderator. This study identifies and examines, using a cross-sectional survey research design, the empirical support for two alternative model - a direct effect model and an indirect effect model of the likely effect of spiritual leadership on employee turnover intention, mediated by quality of work life and organizational climate as moderator on hotel employees of Tanzania. The results of this study showed the inverse relationship of spiritual leadership and turnover intention mediated by quality of work life. In addition organizational climate moderated the effect of quality of work life on turnover intention such that the relationship was stronger when organizational climate was high. The findings from this work adds to the existing literature and provide hotel managers with knowledge on the effects of spiritual leadership on turnover intention of employees. This is an original practical examination and its significance partly comes from its research implications and practice implications.
\end{abstract}

Keywords: Spiritual leadership; Quality of work life; Organization climate; Turnover intention

\section{Introduction}

Small firms are mostly privately owned corporations, sole proprietorships or partnerships that have a small amount of employees. Most of the hospitality sector in Tanzania are privately owned type of business whereby the owner handles all the decisions of the firm. Thus the management of small firms is based on the owner competence to run a business and relies mostly on the leadership of the owner(Ebrahim Hasan Al Khajeh, 2018). The importance of hospitality industries in today's economy through, job creation and economic growth has often been discussed and have been known to contribute to the GDP of Tanzania. Hotels are generally regarded as a type of business where the type of management is traditional; decision making is centralized(Øgaard et al., 2008). Most companies nowadays operate in a competitive economic platform in which they must be very efficient, innovative and also meet the objectives of the company(Yong et al., 2019) with customers' satisfaction. This competitive force calls for hospitality firms to reorganize their internal operations; thus management is a critical role in the hotels' success. In the hospitality sector, employees are vital building blocks of service quality and a strong hotel brand, due to constant interaction between them and customers (Terglav et al., 2016). Therefore, a good leadership would be beneficiary to the hotel's success. Moreover, these business organizations are facing great failures due to poor management, employees' turnover and poor customers' satisfaction and the concept of leadership continues to be the subject of study since the 1920s.

\footnotetext{
* Corresponding author.

E-mail address: Annybird28@gmail.com (Neema Gasper Mariwa)
} 
Leadership over the past decades has been intensively studied but still continues to attract more researchers' cause of its importance in organizations. Defining leadership is a challenge due to the growing amount of literature in the field from which to draw. Spiritual leadership stands in front of us as a type of leadership which has received a lot of interest in the leadership literature in recent years, spiritual leadership has a variety of definitions one of which comprises of the attitudes, values, and behaviors which are essential to intrinsically motivate one's self and others so as they have a sense of spiritual survival through calling and membership (Louis W Fry, 2003). Spiritual leadership is an organizational development and transformation model, which has the potential to lead to organizational evolution to a more optimistic direction and goodness of human within organization as a foundation to reach optimal performance (L. W. Fry \& Matherly, 2007). Practical studies of spirituality in organizations have gained ground. Several authors such as (John et al., 2003), (Giacalone et al., 2005), (Giacalone \& Jurkiewicz, 2010) have all contributed to the mission of defining and measuring spirituality and assessing its impact on organizational performance. Spirituality in workplace is a response for declining and even loss of basic values of employees 'trust in workplace thus leading to employees' turnover.

The aim of this study is to empirically test organizational climate as an antecedent of spiritual leadership and mediating effects of quality of work life on employees' turnover. To better evaluate the influence of spiritual leadership on employees and to understand how it can affects turnover intention, a questionnaire approach was established over the past few months aiming to introduce a new model to improve hospitality firms. This questionnaire has given us a good knowledge for introducing insights into the active and complexity of spiritual leadership on hotel management, in which repetitive activities need flexibility. It is crucial to put more attention on the role of spiritual leadership, its effectiveness and particularly on how spiritual leadership style can be a factor for building flexibility in the framework of a hotel management, reduce turnover intention and to improve the hospitality sector performance and owners' risk bearing. Although numerous studies have been made in different disciplines in the struggle to explore the effects of leadership within establishments and to demonstrate that leadership is a key factor affecting employee's creativity, motivation (Chen \& Hou, 2016; Somech \& Drach-Zahavy, 2011) and turnover intention. There is little knowledge on the impact of spiritual leadership on hotel employees' turnover intention.

Due the above reasons, this study is mostly intended to comprehend spiritual leadership style and its impact on employees' turnover intention through quality of work life which was also suggested by (Samimi et al., 2020) and to do more research on theories that relate spiritual leadership quality of work life, organizational climate and employees' turnover intention.

\section{Literature Review}

\subsection{Theoretical foundations of spiritual leadership}

According to the upper echelon theory leading positions has a major impact on an organization processes and outcomes due to the decisions leaders make(Donald C, 2007). This concept later brought about different forms of leadership one of which is spiritual leadership which focuses on the manager vision and his interaction with his employees. The concept of spiritual leadership was established within an fundamental motivation model that incorporates vision, hope/faith, and altruistic love (Louis W Fry et al., 2005). SL is the use of the leader's spiritual side as a motivational behavior for his subordinates, in such a way that enables them realize the moral strength that binds them together (Lean, Emily, 2002)

Spiritual leadership is a key component in the effective development of some hotels. While these developments may be accepted or criticized, they probably have an intrinsic concept flaw of trying to attempting on improving current patterns of management within the existing model of hospitality management. In the past decade spiritual leadership and the characteristics of a spirituality has been intensively studied and some of the characteristics of a spiritual leader is idealized influence and inspirational motivation(Louis W Fry, 2005). It is indicated that organizational and individual capacities can be augmented through competence, trust, vision, communication of vision and serving others to realize the vision. The main issue with spiritual leadership is the attempt of spiritual leaders to concur with the followers' needs as each individual has his/her needs. 


\subsection{Turnover intention}

Turnover intentions are the thoughts employees have regarding leaving the organization voluntarily at a given period of time (Takase, 2010). Understanding turnover intention rates may help to reduce actual turnover rates and enable strategies that can be applied to avoid the loss of human resource. Therefore, it is important for hotel managers to implement methods to reduce hotel employees' turnover intention, thereby reducing the absence of employees. However, to date, there is no nationwide study on the turnover intention among hotel employees in Tanzania since the large increase of the hospitality sector. Individual personality is identified to be related to whether a hotel employee will leave or stay, for example job scarcity, salary, family status and so forth. Moreover, organization climate and quality of work life as well as the interaction with the leader plays an important role in employee turnover intention.

\subsection{Quality of work life}

Quality of work life was first investigated in the early 70s and was explored from different angles during past decades. One of the experts Walton probed work life in eight different dimensions (rational and satisfactory salary, conducive working environment, providing chances for growth and safety, rules and regulations in organization, social ties, life work, overall living space, integrity of the organization, and development of human capabilities). The observation of employee's opinions about the quality of their work and the quality of their work life gives the employers an idea of where changes can be made in an organization. Quality of work life is changing needs, such as resources, activities and outcomes of participation in work place (Sirgy et al., 2001). Studies and some published works usually propose ethics to either be the foundation of employees' QWL or as a state of working related to QWL. For example, a work environment can be defined as one which provides QWL such as cooperative, evolutionary, open, informal, and interpersonal (Pio \& Tampi, 2018). A working environment of this type can be considered fitting and fruitful because it can be exploited only if managers trust and have confidence in their employees.

\subsection{Relationship between spiritual leadership and employees' turnover}

A relationship between a leader and his followers is a way of improving the quality service of a business and this requires that company work in a broader context that extends beyond itself, and as such no company can be worldclass at everything (Lasserre, 2017). Spiritual leadership is an important tool in management, when used properly can develop a positive relationship with the employees therefore affecting turnover intention. In Africa spirituality is of great importance hence, many employees will feel great and give their full potential when placed in a spiritual environment, thus leading to a low turnover intention.

\subsection{Theoretical model}

In order to fill in the research breach, this study formulates a theoretical model to examine the influence of spiritual leadership on employees' turnover intention using organization climate as moderator and quality of work life as mediator, correlational survey system was used to bring about these hypotheses. In line with the literature review and the aim of this study, the conceptual model in Figure 1 was developed. This concept shows the effect of spiritual leadership on the quality of work life and hence employees' turnover intention. For this objective, firstly investigations were made to test if there is a statistically significant relationship between spiritual leadership and quality of work of life that influences turnover intention. From which the following hypotheses were tested.

Furthermore, scholars have long recognized the importance of spiritual leadership in relation with an organization vision and outcome. The hypotheses tested in the survey were:

Hypotheses 1 : Spiritual Leadership will have a positive direct relationship on quality of work life.

Hypotheses 2 : Spiritual Leadership will have a positive indirect relationship to employee turnover intention through quality of work life

Hypotheses 3 : Organizational climate will moderate the mediated relationship of quality of work life and turnover intention such that the relationship between quality of work life and turnover intention is stronger when organizational climate is low. 


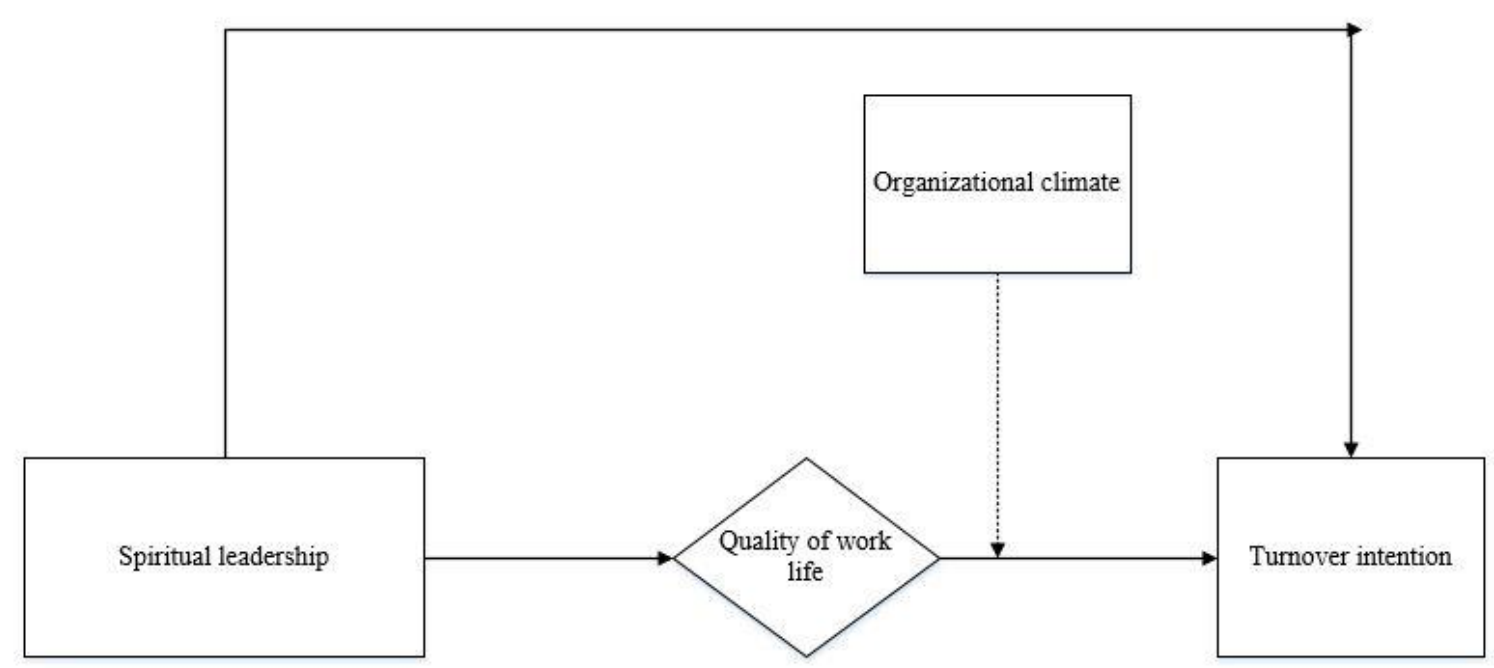

Fig. 1 Theoritical model

\section{Methods}

\subsection{Design, Data collection and participants}

This cross-sectional study was conducted in 2020. Convenience sampling was used for participant recruitment. Registered full-time hotel employees responsible for direct care and indirect care with other workers from other hospitality institutions across Tanzania were invited to participate in this study via online questionnaire. In order to test the clarity and validity of the above hypotheses, a pretest was conducted with 40 employees to determine the effectiveness of the measurement. Based on the feedback achieved, the authors further fine-tuned the modified questionnaire and sent them to different employees. 350 questionnaires were handed out and a total of 260 were received giving a response rate of $73.14 \%$. Participants were predominantly female (63\%) with a mean age of 38.44 and had worked for their organization for an average of 2.33 years.

\subsection{Variables and measurements}

\subsubsection{Spiritual leadership}

The different characteristics of spiritual leadership were measured based on (L. W. Fry \& Matherly, 2007) using a 35item scale, in which five items measured vision, five items measured hope/faith, seven items measured altruism love, four items measured the significance of work, five items measured membership, four items measured commitment, and five items measuring productivity at hotels in Tanzania.

\subsubsection{Quality of work life}

The QWL scale established by was used to evaluate quality of work life. The scale represents a satisfactory approach to QWL, fundamentally based on Maslow's hierarchy of needs theory. In regards to their concepts, organizations that have high scores on QWL are those that make available resources to meet the elementary and growth needs of their employees. The QWL scale entails of two subscales, lower-order QWL and higher-order QWL. A seven-point Likerttype scale ranging from "strongly disagree" (value of 1) to "strongly agree" (value of 7) was used to measure QWL. The QWL scale was also found to be consistent $(\alpha=0.800, \rho=0.789)$. 


\subsubsection{Organizational climate}

Organizational climate measured used a 70 item questionnaire by (Datta \& Singh, 2018) these questionnaires were originally formulated by (Davidson, 2000) which was based on a 5 point likert scale (1=strongly disagree to $5=$ strongly agree). The validity of the scale was confirmed by 3 researchers and 2 hotel managers to validate the construct of the questionnaires, whereas the reliability of the OC item was measured using Cronbach alpha statistic and was found 0.902 which is considered quite high (Darren George \& Mallery, 2018)

\subsection{Turnover intention}

Turnover intention was measured using the 3-item questionnaire from (Cohen, 1998), which queries (1) Thinking a lot about leaving the organization; (2) Actively searching for a new job; (3) As soon as it is possible, I will leave the organization. This scale uses a 5 -point Likert scale from 1 (strongly disagree) to 5 (strongly agree). The total scores were calculated and the mean values, with higher scores indicating more turnover intention. Mean scores $\geq 4$ indicate high-level turnover intention, scores between 2 and 4 indicate uncertainty with turnover intention, and scores $\leq 2$ indicate no turnover intention (Yang \& Chen, 2020). In the present study, the internal consistency coefficient was 0.860 .

\subsection{Data analysis}

Descriptive statistics, reliability tests, t-test, ANOVA and Pearson correlation analysis were employed with the Statistical Package for the Social Sciences (version 20.0). To observe the impact of spiritual leadership, quality of work life on turnover intention, structural equation modeling (SEM) with Robust Weighted Least Squares was conducted to test the hypotheses model with Mplus version 7.0. Path analysis was used to identify direct and indirect effects between the variables with standardized partial regression coefficients shown on the arrows.

\section{Results}

Common method bias (CMB) may affect the results of this study since the data collected used self-reported questionnaires(Fuller et al., 2016; Philip M. Podsakoff et al., 2003). The authors used procedural remedy to test $\mathrm{CMB}$. The procedural remedy that was used guaranteed the anonymity and confidentiality of the participants to reduce social bias. Further confirming CMB was not a serious concern in the current study. A total of 206 hotel employees responded to our survey, out of the 206 participants $73.8 \%$ were female and $26.8 \%$ were male.

Descriptive statistics and correlations of all study variables are displayed in Table 1. We tested our proposed mediation model using SPSS PROCESS macro developed by (Bolin, 2014) and the lavaan package in R (Rosseel, 2012). The results presented in Table 2 , shows the mediated effect of quality of work life. Lastly we tested if this indirect effect is conditional upon organizational climate (Hypothesis 3) due to its moderating effect on the relationship between QWL and employee turnover intention.

Our results showed that SL was positively related to QWL ( $b=0.42, \mathrm{SE}=0.07, \mathrm{p}<.001$ ), and in turn QWL was positively related to employee turnover intention $(\mathrm{b}=0.24, \mathrm{SE}=0.07, \mathrm{p}=.001)$. The indirect effect of $\mathrm{SL}$ on employee turnover intention was significant (indirect effect $=0.10,95 \% \mathrm{CI}=[0.03,0.20]$ ), showing evidence for Hypothesis 2.

We further tested hypotheses 3 to see if organizational climate moderated quality of work life on employee turnover intention. We used the lavaan package in R (Rosseel, 2012) to calculate the index of moderated mediation (Bolin, 2014). Results revealed a significant index of moderated mediation (index $=0.01,95 \%$ bootstrapped $\mathrm{CI}=[0.001$, 0.024]), showing that the direct effect was stronger and more pronounced at high levels of organizational climate (direct effect $=0.16,95 \%$ bootstrapped $\mathrm{CI}=[0.21]$ ) and weaker at high levels of organizational climate (indirect effect $=-0.015,95 \%$ bootstrapped $\mathrm{CI}=[-0.050,-0.002])$. In sum, these analyses support Hypotheses 3 . 
Table 1 Descriptive statistics for measurement scales

\begin{tabular}{lccccccc}
\hline Variables Mean & & Standard deviation & 1 & & 2 & 4 & 5 \\
\hline SL & 4.01 & 0.654 & 0.821 & $(0.92)$ & & & \\
QWL & 3.42 & 0.701 & $0.612^{* * *}$ & $0.71^{* * *}$ & $0.681^{* * *}$ & $(0.89)$ \\
TI & 2.43 & 1.030 & $-0.456^{* *}$ & $-0.234^{* * *}$ & $-0.211^{* * *}$ & $-0.19^{* *}$ & $(0.94)$ \\
OC & 3.94 & 0.837 & $0.678^{* * *}$ & 0.06 & 0.04 & 1.01 & $(0.85)$ \\
\hline
\end{tabular}

Numbers in parentheses on the diagonal are reliabilities of the scales. In this study $\mathrm{N}=206$; and the scale ranged from 1 to $5 . * \star \mathrm{p}<.01 . * * \star \mathrm{p}$ $<.001$.

Table 2 Mediated regression results

\begin{tabular}{|c|c|c|c|}
\hline \multicolumn{4}{|l|}{ Predictors } \\
\hline & & Quality of work life & Turnover intention \\
\hline Intercept & $1.67 * * *(0.35)$ & $6.45^{* * *}(0.50)$ & \\
\hline SL & $0.42 * * *(0.07)$ & $-0.04(0.10)$ & \\
\hline QWL & & $0.32 * *(0.08)$ & \\
\hline $\mathrm{R}^{2}$ & 0.23 & 0.18 & \\
\hline
\end{tabular}

Unstandardized coefficients are reported. Standard errors are in the brackets.

$* \mathrm{p} \leq .05, \quad * * \mathrm{p} \leq .01, \quad * * * \mathrm{p} \leq .001$.

Table 3 Moderated regression results

\begin{tabular}{|c|c|c|c|}
\hline \multirow[t]{2}{*}{ Predictors } & \multicolumn{2}{|c|}{ Criterion variables } & \multirow{3}{*}{ Turnover intention } \\
\hline & & Quality of work life & \\
\hline Intercept & $1.27 * *(0.28)$ & $3.57 * * *(0.55)$ & \\
\hline SL & $0.42 * * *(0.07)$ & $-0.04(0.10)$ & \\
\hline QWL & & $0.32 * *(0.08)$ & \\
\hline $\mathrm{OC}$ & $0.16(0.11)$ & $0.21(0.12)$ & \\
\hline $\mathrm{QWL} \times \mathrm{OC}$ & & $0.09(0.08)$ & \\
\hline $\mathrm{R}^{2}$ & 0.34 & 0.22 & \\
\hline
\end{tabular}

Unstandardized coefficients are reported. Standard errors are in the brackets.

$* \mathrm{p} \leq .05, \quad * * \mathrm{p} \leq .01, \quad * * * \mathrm{p} \leq .001$

\section{Discussion}

Employees' turnover intention is a key role in determining an organizational achievement. In this research, we argued that spiritual leaders can inhibit employee turnover intention by increasing quality of work life, which, in turn, reduces turnover intention among employees. We further argued that employee organizational climate mitigates the quality of work life triggered by spiritual leaders. Across the study conducted in Tanzania, we found solid evidence on our proposed theoretical model. The results obtained proved that SL undermines employees' turnover intention, with the relationship between SL and turnover intention mediated by quality of work life. Furthermore our results showed that organizational climate moderated the relationship between QWL and turnover intention such that the relationship was stronger when organization climate was high. Our study brings contributions to the existing literature. First, our study validates emerging research suggesting that SL has a significant impact on the quality of work life of employees(Nafei, 2018). Regardless of existing work there is still lack of knowledge on why and how SL affects employee turnover intention. Accordingly we developed a model to better understand the relationship 
between SL and turnover intention through quality of work life. Our findings suggest that employees' turnover intention is stimulated when the quality of work life is low and the SL does not focus on the organization goal.

Secondly rather than just displaying a direct relationship between SL and turnover intention, our study provides a more profound understanding of why SL affects turnover intention. In doing so we addressed the link between SL, QWL and turnover intention. Up till date SL has been focused on its influence on quality of work life, job satisfaction (Almalki et al., 2012; Masouleh, Saeid Askari Koochaksaraei et al., 2013). Our research proves that quality of work life plays an important role in linking SL with employee turnover intention. That is if the wages justice, social integration, opportunities created by the spiritual leader are good the employees' will have less intentions of turnover. Moreover, our study provides supplementary insights and broadens what we know about employees' turnover intention to SL.

Thirdly we also contribute to the literature by examining organizational climate as a moderator of QWL's impact on turnover intention. Although organizational climate has been identified as an important key in the management of hotels (Subramaniam, 2013) that could be useful in directing quality of work life.

Future research could also explore the role of other theoretically driven moderating variables that could impact the SL - turnover intention link or other mediating variables. For example, future research could focus on the impact of psychologic capital, or, individual power distance orientation or other organizational resources that hinders employees' turnover intention.

\section{Conclusion}

In conclusion, our study shows how SL influences employee turnover intention through its relationship with quality of work life and makes significant contributions to leadership and turnover literatures by bringing a more elaborate view on how SL influence employee turnover intention. Moreover we also highlighted the role of organizational climate on quality of work life. The need for managers to have the element of hope and faith in the employees for the good functioning of the Organization, since they are the building blocks of the Organization and the organization vision can be achieved, through rewarding material rewards on the one hand and involvement in their development on the other.

\section{Acknowledgements}

Authors want to thank Jiangsu University for their immense support.

\section{References}

Almalki, M. J., FitzGerald, G., \& Clark, M. (2012). The relationship between quality of work life and turnover intention of primary health care nurses in Saudi Arabia. BMC Health Services Research, 12, 314. https://doi.org/10.1186/1472-6963-12-314

Bolin, J. H. (2014). Hayes, Andrew F. (2013). Introduction to Mediation, Moderation, and Conditional Process Analysis: A Regression-Based Approach. New York, NY: The Guilford Press. Journal of Educational Measurement, 51(3), 335-337. https://doi.org/10.1111/jedm.12050

Chen, A. S.-Y., \& Hou, Y.-H. (2016). The effects of ethical leadership, voice behavior and climates for innovation on creativity: A moderated mediation examination. The Leadership Quarterly, 27(1), 1-13. https://doi.org/10.1016/J.LEAQUA.2015.10.007

Cohen, A. (1998). An examination of the relationship between work commitment and work outcomes among hospital nurses. Scandinavian Journal of Management, 14(1), 1-17. https://doi.org/https://doi.org/10.1016/S09565221(97)00033-X 
Darren George, \& Mallery, P. (2018). IBM SPSS Statistics 25 Step by Step: A Simple Guide and Reference (15th ed.).

Datta, A., \& Singh, R. (2018). Determining the dimensions of organizational climate perceived by the hotel employees. Journal of Hospitality and Tourism Management, 36, 40-48. https://doi.org/https://doi.org/10.1016/j.jhtm.2018.07.001

Davidson, M. C. G. (2000). Organisational climate and its influence upon performance: A study of Australian hotels in South East Queensland.

Donald C, H. (2007). Upper Echelons Theory: An Update. Academy of Management Review, 32(2), 334-343. https://doi.org/10.5465/amr.2007.24345254

Ebrahim Hasan Al Khajeh. (2018). Impact of Leadership Styles on Organizational Performance. Journal of Human Resources Management Research, 2018(2166-0018), 10.

Fry, L. W., \& Matherly, L. L. (2007). Workplace Spirituality, Spiritual Leadership and Performance Excellence. In Encyclopedia of Industrial/Organizational Psychology. San Francisco: Sage.

Fry, Louis W. (2003). Toward a theory of spiritual leadership. The Leadership Quarterly, 14(6), 693-727. https://doi.org/https://doi.org/10.1016/j.leaqua.2003.09.001

Fry, Louis W. (2005). Introduction to the leadership quarterly special issue: Toward a paradigm of spiritual leadership.

Fry, Louis W, Vitucci, S., \& Cedillo, M. (2005). Spiritual leadership and army transformation: Theory, measurement, and establishing a baseline. The Leadership Quarterly, 16(5), 835-862. https://doi.org/https://doi.org/10.1016/j.leaqua.2005.07.012

Fuller, C. M., Simmering, M. J., Atinc, G., Atinc, Y., \& Babin, B. J. (2016). Common methods variance detection in business research. Journal of Business Research, 69(8), 3192-3198. https://doi.org/https://doi.org/10.1016/j.jbusres.2015.12.008

Giacalone, R., \& Jurkiewicz, C. (2010). Toward a Science of Workplace Spirituality. In Toward a science of workplace spirituality. The handbook of workplace spirituality and organizational performance.

Giacalone, R., Jurkiewicz, C., \& Fry, L. (2005). From Advocacy to Science The Next Steps in Workplace Spirituality Research. Handbook of the Psychology of Religion and Spirituality.

John, M., J., C. A., \& Jeffery, F. (2003). Workplace spirituality and employee work attitudes: An exploratory empirical assessment. Journal of Organizational Change Management, 16(4), 426-447. https://doi.org/10.1108/09534810310484172

Lasserre, P. (2017). Global Strategic Management (4th ed.). Macmillan International Higher Education.

Lean, Emily, R. (2002). The Construct Development Of Spiritual Leadership. University of Arkansas.

Masouleh, Saeid Askari Koochaksaraei, H. M., Saeedi, N., \& Mousavian, S. I. (2013). Studying the relationship between spiritual leadership and job satisfaction. Psychology.

Nafei, W. A. (2018). Spiritual Leadership and Quality of Work Life an Exploratory Study on Menoufia University Hospitals. Case Studies Journal, 7.

Øgaard, T., Marnburg, E., \& Larsen, S. (2008). Perceptions of organizational structure in the hospitality industry: Consequences for commitment, job satisfaction and perceived performance. Tourism Management, 29(4), 661671. https://doi.org/10.1016/J.TOURMAN.2007.07.006

Philip M. Podsakoff, Scott B MacKenzie, J.-Y. L., \& Podsakoff, N. P. (2003). Common method biases in behavioral research: a critical review of the literature and recommended remedies. The Journal of Applied Psychology, 88(5), 879-903.

Pio, R., \& Tampi, J. (2018). The influence of spiritual leadership on quality of work life, job satisfaction and 
organizational citizenship behavior. International Journal of Law and Management, 60, 0. https://doi.org/10.1108/IJLMA-03-2017-0028

Rosseel, Y. (2012). lavaan: An R Package for Structural Equation Modeling. Journal of Statistical Software; Vol 1, Issue 2 (2012) . https://doi.org/10.18637/jss.v048.i02

Samimi, M., Cortes, A. F., Anderson, M. H., \& Herrmann, P. (2020). What is strategic leadership? Developing a framework for future research. The Leadership Quarterly, 101353. https://doi.org/10.1016/J.LEAQUA.2019.101353

Sirgy, M. J., Efraty, D., Siegel, P., \& Lee, D.-J. (2001). A New Measure of Quality of Work Life (QWL) Based on Need Satisfaction and Spillover Theories. Social Indicators Research, 55(3), 241-302. https://doi.org/10.1023/A:1010986923468

Somech, A., \& Drach-Zahavy, A. (2011). Translating Team Creativity to Innovation Implementation: The Role of Team Composition and Climate for Innovation. Journal of Management, 39(3), 684-708. https://doi.org/10.1177/0149206310394187

Subramaniam, I. D. (2013). Perceived Organizational Climate and Turnover Intention of Employees in the Hotel Industry. World Applied Sciences Journal, 22, 1751-1759.

Takase, M. (2010). A concept analysis of turnover intention: Implications for nursing management. Collegian, 17(1), 3-12. https://doi.org/https://doi.org/10.1016/j.colegn.2009.05.001

Terglav, K., Konečnik Ruzzier, M., \& Kaše, R. (2016). Internal branding process: Exploring the role of mediators in top management's leadership-commitment relationship. International Journal of Hospitality Management, 54, 1-11. https://doi.org/10.1016/J.IJHM.2015.12.007

Yang, Y., \& Chen, J. (2020). Related Factors of Turnover Intention Among Pediatric Nurses in Mainland China: A Structural Equation Modeling Analysis. Journal of Pediatric Nursing, 53, e217-e223. https://doi.org/https://doi.org/10.1016/j.pedn.2020.04.018

Yong, J. Y., Yusliza, M.-Y., Ramayah, T., \& Fawehinmi, O. (2019). Nexus between green intellectual capital and green human resource management. Journal of Cleaner Production, 215, 364-374.

https://doi.org/10.1016/J.JCLEPRO.2018.12.306 